\title{
REVIEW ON ORGANIZATIONAL CHANGE IN THE FIELD OF LEAN MANUFACTURING
}

\section{SASMITAMOHANTY \& BIBHUTI B PRADHAN}

Department of Management, Siksha 'O' Anusandhan (Deemed to be University), Bhubaneswar, Odisha, India

\begin{abstract}
"Lean manufacturing systems" is commonly used in industrial industries around the world. The poor success rate of lean transitions has, however, provided reason for concern in several countries. Most of the research has found out that the key explanation for this was the inability to handle the transition cycle during a lean manufacturing transformation. Lean manufacturing is now a commonly recognized and implemented best practice in production across countries and sectors today. A lean organisation's primary aim is to build an efficient, high quality operation that can deliver finished goods with little to no waste at the pace of consumer demands.This paper provides a comprehensive analysis of the literature in the sense of corporate change management for lean manufacturing strategies. Furthermore, the researchers suggested a lean production application operational transition structure that would serve as the foundation for more scientific analysis and evaluation. The methodology would also extend the information base by integrating management of internal transformation with the change to introducing a lean manufacturing program.

KEYWORDS: Critical Success Factors, Framework Development, Lean Manufacturing, Organisational Change, Scientific Evaluation
\end{abstract}

Received: Jun 08, 2020; Accepted: Jun 28, 2020; Published: Sep 07, 2020; Paper Id.: IJMPERDJUN202010100

\section{INTRODUCTION}

The growing obstacles faced in today's global market have driven several manufacturing firms to introduce modern production management techniques to boost the productivity and profitability of the business. Any industrial companies have embraced lean industrial as a marketing method, and lean methods are used in several specific ways, and are known under numerous names. Lean manufacturing is now a commonly recognized and implemented best practice in production across countries and sectors today. A lean organisation's primary aim is to build an efficient, high quality operation that can deliver finished goods with little to no waste at the pace of consumer demands[1].

However, in practice, many organizations were not capable of transforming themselves into lean manufacturing enterprises that can be known as world-class businesses. Progression toward lean manufacturing is full of terrific challenges. It was reported that several lean manufacturing implementations at a certain point in the implementation, even those conducted with the good intentions, have often been destined for failure. In general, lean manufacturing in terms of scale and quality should be applied holistically and comprehensively[2].

Several researchers concluded that the change from conventional to lean world is not a production or technological problem, but instead a culture adjustment within the organizational question. Typically transition to lean production requires a drastic change in an organisation's organization, policy, and technological factors. The 
adoption of lean manufacturing program requires time, according to experts, because workers need to grasp the principles underlying lean manufacturing, in order to improve their ability to conform to the method. Simple awareness in handling these improvements is therefore of vital importance in achieving a productive, lean transition[3].

Most of the literature published had addressed the lean production transition in considerable depth but relatively few had examined it from an operational change management viewpoint. A detailed review by scholars on the lean manufacturing environment revealed that much of the current lean manufacturing system is known as "design / conceptual process". These structures do not explain how lean manufacturing is to be applied and do not demonstrate how every factor of lean manufacturing is linked to an implementation organisation. This paper therefore provides an analysis of the corporate change management in the application of lean manufacturing.

It also addresses the variables driving companies in the move to lean fabrication method. The paper starts with a comprehensive literature analysis based on context, development of the idea, regression in application of lean manufacturing and management of internal change. Finally, a structure for systemic reform in the application of lean manufacturing has been developed which will ideally serve as the foundation for more scientific study and testing[4].

This concept is of special significance not only because it applies to lean manufacturing, but also because it is placed in the sense of process change in lean manufacturing transformation, which will inevitably be pursued in the future by several firms who want to be more efficient. This guide is intended to provide clinicians a deeper definition of lean transformation and unambiguous guidelines, and/or methods to reduce the difficulty and disagreements of adopting a lean production program[5].

\section{Evolution of Lean Manufacturing}

Lean manufacturing is not a novel invention. This definition has developed from a technologically focused perspective to a human-centred dimension over the last decades. The human elements of lean manufacturing reflect the philosophy and cooperation of the organization, which involve labour efficiency, multi-skilled component, and greater accountability for upkeep, enhancement of production, and personnel problems. The lean production idea was first adopted as a shop floor method to attain higher performance, because it is applied through the just-in-time (JIT) or Toyota Production System (TPS) framework[6].

The TPS and JIT system have become one of the descent management strategies for improving business performance together with achieving improved overall quality management. In his analysis of lean manufacturing history, researchers also highlighted that many early writers focused largely on shop floor techniques and reduction of inventories. By the 1990s, the idea of waste management and value-added factors of the supply chain was created. In Japanese, the "waste" or "muda" is everything but the total sum of machinery, products, components, and working time that is necessary for development. There are 7 main waste forms as seen in Figure 1. 


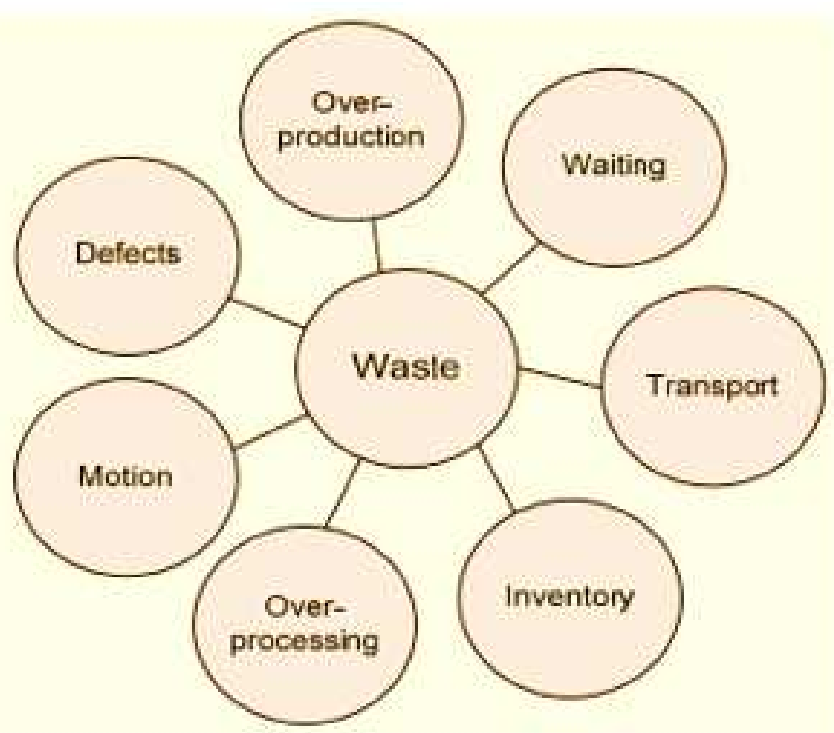

Figure. 1: Seven Types of Waste

Figure 1

Waste may arise from defects in overproduction, waiting time, shipping, distribution, manufacturing, travel, and the product. The novel, lean thought helps to explain the concepts of becoming lean: recognizing consumer interest, defining interest-added behaviours in value stream, creating flow (consumer value), pulling method and quality development to excellence. While analysts claimed that this lean production model and methods was more modern relative to prior models as it can be applied in different forms of businesses and societies[7].

After 2000 the lean definition has included a larger degree of flexibility and the spectrum has been extended to incorporate the experience of corporate learning. Any observers felt the lean idea will have a better likelihood of evolving and maturing in the future. Evolution may be contrasted with organizational learning in a staggered cycle. They assumed that lean fabrication was a multifaceted method. Lean machine interconnected design requires both individuals and method elements. It is often connected to the business (i.e. internal), and the products of manufacturers and consumers (i.e. external).

Researchers identified that the lean model works on two main principles in their report on Toyota: "continuous change" and "respect for people". Many senior executives outside Toyota have overlooked and mistaken the concept of "respect for people" as opposed to "continuous improvement". Lean manufacturing is grounded in a philosophy of kaizen or quality improvement that needs the knowledge and a common way of thought to consistently eradicate duplication and maximize operation efficiency. The lean definition has now evolved to a level that involves knowledge-creation management, and seeks to build a learning organization, through which citizens shape the core of lean operation[8].

Lean manufacturing is a manufacturing technique aimed at ensuring seamless output flow by reducing waste and increasing the efficiency of the operation. Many experts also point out that if an enterprise follows the lean production approach, the business will not be willing to have a chance of better output, quicker delivery and reduced prices against the existing global market. In a broad cross-country study, lean production practices proved capable of generating highperformance businesses. 


\section{Implementation Failure}

Lean manufacturing is a fabrication technique aimed at creating a seamless output flow by reducing waste and increasing the efficiency of the operation. Several analysts found out that if a company follows the lean production approach, in terms of better efficiency, quicker output, and reduced prices it will not be able to stand a chance against the new global market. This argument is also reinforced by a broad cross-country study by analysts showing that lean production approach of every company produces strong efficiency. However, it's not an easy job to turn from a conventional industrial method to lean growth [2].

The transition includes paying emphasis to the effect on both the mechanism and the individuals. Despite the comprehensive spotlight of benefits obtained by adopting lean manufacturing, in reality not many businesses are effective in adopting lean manufacturing. There are several documented issues and concerns surrounding the lack in introducing lean production[9].

\section{Organizational Change System}

From the above literature review it is obvious that a structure is needed in the implementation of lean manufacturing. The two key goals of this process was to include efficiency improvement by the introduction of a lean manufacturing program in production firms, and also to aid in the incorporation of lean manufacturing through the businesses. The structure suggested in Figure 2 is an extension of the researchers existing organizational change system.

By expanding this conceptual concept and developing a more precise lean manufacturing strategy, the writers are able to define and integrate the organizational change factors and essential success factors that will allow the system to function and ensuring that the organizational change factors stay as the central and integral elements of this method.

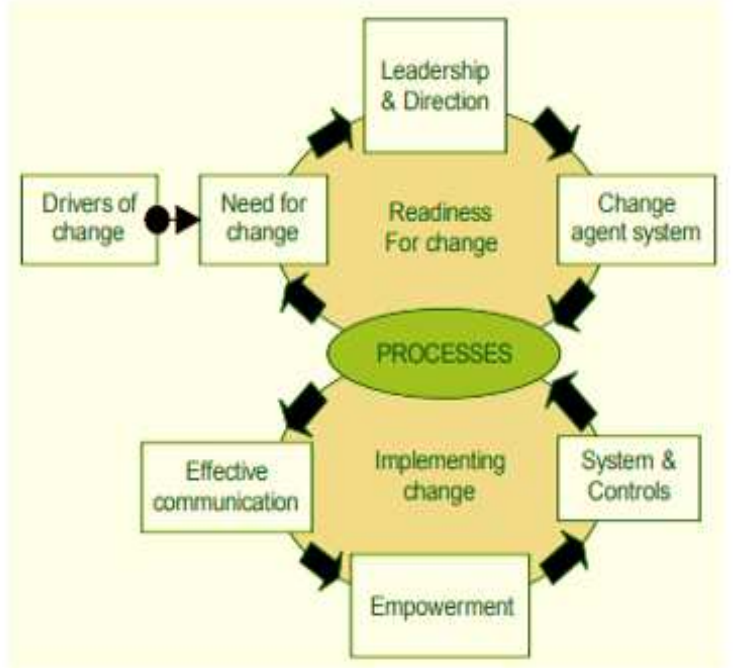

Figure 2: Organisational Change Framework in Lean Manufacturing Implementation

Figure 2

The system specifically demonstrates the main stages of manufacturing implementation leaning in the process. The most fundamental phase of this system consists of two cycles: first, the preparation for transition, and second, the execution of transition. However, a sense of urgency has to be built before a firm is ready for transition. The reasons for 
moving to a lean manufacturing method can derive from competing commodity pressures on the domestic and foreign markets. Competitive goods need technology innovation, innovation in efficiency and a reduction in operating costs [3].

It is also the top management's duty to insure that such forces of transformation are well articulated and developed and build the sense of urgency for a lean production environment to be improved. The organisation and the employees employed in the company will be ready for the transition in order for the shift to take place and flourish. Failure to evaluate systemic and person improvements may result in a significant deal of time, effort and hard work being expended. Both of these variables tackle the aversion to change because it needs a lot of operational danger.

It is important to resolve the desire for change by recognizing and acknowledging the need for change, providing transparent and reliable guidance and direction, and building a stable team of change agents. This is where the position of top management in transitioning into a lean manufacturing method is important. This is advised that top management develop and distribute the expectations and priorities that can be linked to almost any person within the company. High leadership types would demonstrate outstanding system management techniques, permeate direction and adjust plan approach, which will strongly inspire the labour force [5].

First, the establishment of a robust network of change agents is critical in building the capacity to change. A change agent program is a device that helps with the implementation of the transition method such that more employees in the business can grasp lean production principles. The position of lean change agent is critical because most workers are not comfortable with the current lean work setting, and due to the specific success and importance requirements it needs a shift of behaviour and attitude. It is also critical that those who are driving the transition initiatives will have the experience, experience and aptitude to adopt lean manufacturing.

It is not a straightforward process to turn from conventional production method to lean manufacturing. Researchers say that effective adoption of lean manufacturing relies on four crucial factors: leadership and management; finance; knowledge and expertise; and the organization's positive corporate culture. Several studies say that implementing the complete range of lean concepts and equipment often leads to the effective lean manufacturing transition

\section{LITERATURE REVIEW}

Lean manufacturing is a fabrication technique aimed at ensuring seamless output flow by reducing waste and increasing the efficiency of the operation. Many experts also point out that if an enterprise follows the lean production approach, the business would not be able to have a chance for better output, quicker delivery and reduced prices against the increasing global market. In a broad cross-country study, lean production practices proved capable of generating high-performance businesses [6].

It is not a straightforward process to turn from conventional production method to lean manufacturing. Researchers say that effective adoption of lean manufacturing relies on four crucial factors: leadership and management; finance; knowledge and expertise; and the organization's positive corporate culture. Some studies say that implementing a complete range of lean concepts and methods often leads to the effective implementation of lean production.Transition is not an anomaly today but a gradual phase moving forward. Changes involve sensitivity to the method and human impacts. Organizational progress management methodology centres on ensuring the people aspect of transition are handled correctly consistent with corporate policy, infrastructure and organizational processes. Researchers describe organizational transition 
as the mechanism by which organizations shift from their current state to a new state in order to improve their effectiveness [7].

Lean welding reflects a systematic solution to transition. To promote a philosophy of quality development, several programs are set in motion. A major systemic and institutional transition will arise within the company, in order to build the basis for lean production to take place. Top management support and dedication are crucial in ensuring the lean manufacturing performance and sustainability. Certain critical considerations include workplace commitment to lean production programs, and preparation or training. Empowerment of the workers may only be accomplished through proper preparation on philosophy and fundamental concepts, and even lean manufacturing purposes [8].

A case study on two effective businesses in sustaining transition towards lean manufacturing showed that management engagement, collaboration, mobilization of the workers and enhancement of ownership through a methodical lean education program and motivation, and lean culture growth are necessary to maintain progress towards leanness. This confirms the study that expenditure in industrial services such as quality control, community problem-solving, training and staff empowerment are the main moves towards effective lean manufacturing [9].

Following clarification on preparation for transition, the next step the business will take is to take the lean methods and strategies or processes as outlined in Figure 2 and incorporate them. Researchers acknowledged that the primary aim of lean resources is to illustrate and classify the organisation's excess or issues. When the root cause is known, a continual enhancement of the program is feasible. Since lean manufacturing is regarded as a method, this system's methods and techniques cannot be implemented in isolation. Both strategies are built in lean production to promote the application of lean concepts and the overarching approach of the organization[10].

As the new framework's top circle emphasizes mainly on participating in strategic collaboration, the lower circle highlights the needs to be identified, assessed, and accepted. In lean production the deployment transition time is rather important. Implementing the transition will be coordinated with the organizational problems, so that employees inside the organisation will appreciate how they would impact and what needs to be accomplished to resolve the organization's difficulties. The key factors for lean performance are good communication, education and preparation, and the program and regulation[11].

Once the moves move to the procedures for seamless systemic improvement that lets the systems function or not, the lower circle of the system shuts, culminating in potentially successful lean manufacturing implementation. After positive change management process, usually the organization accepts the transition. Taking another ride around the circle would validate the cycle of transformation and reinforces lean production in the world of business, where improvements have been part of "the way they do it here". Persistence is really critical for preserving the improvements produced. Sustainability can be accomplished by consolidating progress and bringing in further change[12].

\section{CONCLUSIONS}

The researchers of this paper traced the history of lean manufacturing from its early Toyota origins and its development into a more nuanced and popular term that is common in many industries and nations. This research, while highlighting the advantages gained by introducing lean production, nevertheless made it evident that transitioning to lean is very difficult. The key factor for this task is the role of transformation within the organization, in several ways and phases. While several research on individualistic change factors or any of the organizational change factors have been performed to the full 
understanding of the scholars, there is little study aimed at creating a structure that will enable an enterprise to transition into a lean production environment. In this present work, a framework for organizational change to implement lean manufacturing is suggested which serves as the basis for further empirical research and validation.

Moreover, this approach has significant benefits as it specifically describes the interaction between handling transformation and introducing lean manufacturing.This work is among the few to relate organizational change management to the introduction of lean manufacturing method. The paradigm indicates that a radical change in transition planning, leadership and management, transition agent program, team creation and mobilization, connectivity, and evaluation mechanism is needed in order to incorporate lean manufacturing method. The suggested structure may also constitute an innovative method to clarify the general definition for applying lean manufacturing program. Moreover, many practitioners are eager to adopt lean manufacturing program specifically for SMEs, but the implementation phase is characteristically fraught with confusion.

\section{REFERENCES}

1. D. L. Goetsch and S. B. Davis, "Quality Management for Organizational Excellence: Introduction to Total Quality," Pearson, 2016.

2. D. L. Goetsch and S. B. Davis, "Quality management for organizational excellence," TQM It really Work., 2010.

3. R. Chavez, W. Yu, M. Jacobs, B. Fynes, F. Wiengarten, and A. Lecuna, "Internal lean practices and performance: The role of technological turbulence," Int. J. Prod. Econ., 2015.

4. W. A. Kahn, "Leadership and change," in Holding Fast, 2010.

5. V. Gupta, P. Acharya, and M. Patwardhan, "A strategic and operational approach to assess the lean performance in radial tyre manufacturing in India: A case based study, "Int. J. Product. Perform. Manag., 2013.

6. S. Bhasin, Lean Management Beyond Manufacturing. 2015.

7. G. Abrahamsson, H. Englund, and J. Gerdin, "Organizational identity and management accounting change," Accounting, Audit. Account. J., 2011.

8. S. Bhasin, Lean management beyond manufacturing: A holistic approach. 2015.

9. M. Taleghani, “* Key factors for implementing the lean manufacturing system,” Science (80-. )., 2010.

10. K. B. Stone, "Lean transformation: Organizational performance factors that influence firms' leanness," J. Enterp. Transform., 2012.

11. G. D. Putnik and Z. Putnik, "Lean vs agile in the context of complexity management in organizations," Learn. Organ., 2012.

12. R. de C. Freitas, M. do C. D. Freitas, G. Gomes de Menezes, and R. S. Odorczyk, "Lean Office contributions for organizational learning," J. Organ. Chang. Manag., 2018. 
